\title{
Self-rated health and trust in low-income Mexican-origin individuals in Texas ${ }^{\text {is }}$
}

\author{
Luisa Franzini* \\ Department of Management, Policy, and Community Health, School of Public Health Houston, University of Texas, \\ RAS 9231200 Herman Pressler Drive, Houston, TX 77030, USA
}

\section{A R T I C L E I N F O}

\section{Article history:}

Available online 24 October 2008

\section{Keywords:}

Mexican-Americans

Self-rated health

Trust

USA

Neighborhood

Low income

Race/ethnicity

Linguistic fragmentation

\begin{abstract}
A B S T R A C T
The evidence suggests that trust is an important determinant of health. Trust tends to be lower in low-income and minority individuals, who already suffer from worse health. Therefore, it is particularly important to investigate the predictors of trust in disadvantaged individuals. In this article we use multilevel models to investigate the individual and neighborhood predictors of trust in Mexican-Americans living in low-income neighborhoods (defined as census block groups) in Texas. Detailed survey data on 1754 Mexican-origin respondents provided information on self-rated health and individual characteristics including sociodemographic and sociocultural personal characteristics (frequency of association with people of other races/ethnicities, social support, perceived racism, perceived personal opportunity, and religiosity). Neighborhood heterogeneities and socioeconomic status, computed from census data, were supplemented by community social characteristics (collective efficacy and public disorder) obtained from survey data. Trust was a significant predictor of self-rated health in our sample. This study suggests that MexicanAmericans tend to trust more those with whom there is likely to be a personal acquaintance than other Mexican-Americans. Furthermore, while the results of this study support that people tend to trust more those who are like themselves, for Mexican-Americans, the identification of who is more alike is not based exclusively on racial/ethnic identity, but is a complex process based also on linguistic and socioeconomic similarities. In our sample, linguistic fragmentation, but not racial/ethnic diversity nor neighborhood impoverishment, correlated with trust. Ease of communication seemed to be more important than racial/ ethnic homogeneity in encouraging interpersonal trust among Mexican-Americans at the neighborhood level. The findings in this study imply it may be possible to develop neighborhood level interventions, focusing on encouraging social interaction in racially/ethnically and linguistically diverse communities, with the aim of promoting trust to improve health outcomes.
\end{abstract}

(c) 2008 Elsevier Ltd. All rights reserved.

\footnotetext{
is This study was part of a project funded by a Texas Department of Health Innovation Grant (2000-2003) and was approved by Committee for the Protection of Human Subjects of The University of Texas Health Science Center at Houston (HSC-SPH-00-064). I am indebted to Norma Perez and Melissa Montoya for coordinating the data collection, and to Ben Amick, Margaret Caughy, Jan Risser, Maria Eugenia FernandezEsquer, and Bill Spears who contributed to the project.

* Tel.: +1 7135009487 .

E-mail address: luisa.franzini@uth.tmc.edu
}

\section{Background}

Trust is an important determinant of health. At the micro level, individuals who trust more tend to be healthier (Poortinga, 2006). The preponderance of the literature indicates that, at the macro level, regions and neighborhoods with more social capital, reflecting a more trusting community, have better health outcomes (Carlson, 2004; Kavanagh, Turrell, \& Subramanian, 2006; Kim \& Kawachi, 2006; Kim, Subramanian, Gortmaker, \& Kawachi, 2006; 
Mellor \& Milyo, 2005; Nummela, Sulander, Rahkonen, Karisto, \& Uutela, 2008; Subramanian, Kim, \& Kawachi, 2002; Yip et al., 2007). Lower trust has been associated with major causes of deaths (Kawachi, Kennedy, Lochner, \& ProthrowStith, 1997) and with worse self-reported health (Subramanian et al., 2002). Only a few studies have reported a lack of association between trust and health outcomes in specific populations (Drukker, Buka, Kaplan, McKenzie, \& Van Os, 2005; Lindstrom \& Lindstrom, 2006).

Because of the importance of trust to health outcomes, more needs to be known about what determines trust levels in individuals and communities. Researchers in sociology, social psychology, economics, and political sciences have investigated determinants of trust at the individual level (Alesina \& La Ferrara, 2002; Cook, 2001; Hardin, 2002; Putnam, 2000; Welch et al., 2005). But only a few papers address the community level predictors of trust (Alesina \& La Ferrara, 2002; Cohen, Inagami, \& Finch, 2008; Leigh, 2006). Inequalities in income, racial diversity, and linguistic fragmentation have been linked to lower trust levels in countries, cities, and neighborhoods (Alesina \& La Ferrara, 2002; Leigh, 2006; Putnam, 2000, 2007). Those studies support the notion that people trust more those like themselves (same race/ethnicity or SES) and therefore lower trust levels are somehow inevitable in diverse communities.

It is particularly important to investigate the predictors of trust in low-income and minority communities because it is known that trust tends to be lower in those disadvantaged communities (Alesina \& La Ferrara, 2002; Leigh, 2006). It is also well known that minority individuals report lower trust levels than members of the majority (Alesina \& La Ferrara, 2002; Leigh, 2006). Thus, lower trust levels could be an additional contributor to worse health outcomes in disadvantaged communities.

In this article, we want to explore the predictors of trust among minorities, especially economically disadvantaged minorities. Specifically, we investigate the association of different types of trust with self-rated health and the predictors of trust in Mexican-origin individuals living in low-income neighborhoods (defined as census block groups) in Texas. Texas is one of the states in USA with the lowest trust levels (Alesina \& La Ferrara, 2002). A previous paper (Franzini \& Fernandez-Esquer, 2004), using the same population of Mexican-origin individuals and focusing on the role of acculturation (nativity/language use) on health and on the contribution of sociocultural personal factors to differences in health by nativity/language, identified trust as an important predictor of self-rated health. This paper focuses on better understanding of the role of trust on selfrated health and the predictors of trust in this disadvantaged minority with the hope to provide evidence that can be used to inform community level programs aimed at building trust.

Detailed survey data provided information on individual sociodemographic characteristics such as gender, age, selfreported race/ethnicity, nativity, language use, education, household income, and time lived in the neighborhood. Questions on trust addressed several distinct dimensions of trust. Because of the large number of immigrants from Mexico in our sample, we asked about trust in people in the U.S. and people in Mexico. Information was collected on individual sociocultural personal characteristics, such as frequency of association with people of other races/ethnicities, social support, perceived racism, perceived personal opportunity, and religiosity. Neighborhood heterogeneities and socioeconomic status, computed from census data at the block group level, were supplemented by community social characteristics obtained from survey data, such as collective efficacy and social and physical public disorder (Sampson \& Raudenbush, 2004; Sampson, Raudenbush, \& Earls, 1997).

This is the first study, to our knowledge, that investigates the predictors of trust in a minority population. We contribute to the existing literature on trust by using more detailed data on individual and community characteristics and by defining the community at the block group level, which may be more relevant to how individuals develop trust.

\section{A model for predictors of trust}

\section{Individual level predictors}

We include in the model the following individual demographic and socioeconomic factors: age, gender, race/ ethnicity, nativity, non-English speaker, income, and education. To the extent that trust can be considered a "moral and cultural attitude", individual characteristics, such as age, gender, and socioeconomic status, can influence this attitude (Alesina \& La Ferrara, 2002). Individuals who are older, are males, have more education and income, and are working tend to report more trust (Alesina \& La Ferrara, 2002; Leigh, 2006). Those individuals are likely to have more resources and be able to use them more efficiently when making decisions about trust.

Members of groups who have been discriminated in the past, such as minorities, women, and those of lower status, may be less likely to trust others because of experiences of negative interactions with others (Alesina \& La Ferrara, 2002). Minorities in particular, tend to report lower trust levels. This could be because people tend to trust more people like themselves and minorities, when answering questions about general trust, may interpret general trust as trust in the majority population, a group different from themselves. Immigrants and non-English speakers are expected to be less trusting for similar reasons. Non-English speakers have the added disadvantage of difficulties in communicating.

Other individual characteristics included in the model are sociocultural personal characteristics that are expected to influence trust, such as length of residence in the neighborhood, associations with other races/ethnicities, perceived personal opportunities, perceived racism, social support, and religiosity. Long time residents are likely to be more socially integrated and to know neighbors for a longer period of time, breeding familiarity and expectations of future reciprocal interaction based on cooperation which encourage trust (Coleman, 1990). Empirically, long term residents report more trust (Alesina \& La Ferrara, 2002). Individuals who mix with people of different race/ethnicity are more likely to have lower "aversion to heterogeneity", defined as more positive attitudes toward racial/ethnic mixing. Empirically, individuals with lower levels of "aversion to heterogeneity" living in racially fragmented neighborhoods have been shown to trust more than similar 
residents with higher levels of "aversion to heterogeneity" (Alesina \& La Ferrara, 2002). Perceived personal opportunities indicate optimism in the future, which may also encourage trusting. Perceived personal opportunities have been linked to positive physical and mental health and are especially relevant among foreign born as perceptions of opportunities draw immigrants to their new country (Franzini \& Fernandez-Esquer, 2004). Perceived racism refers to the subjective experience of prejudice or discrimination. Perceived racism is likely to influence trust as those who have experienced discrimination and being treated unfairly are less likely to trust. Positive interaction experiences among individuals with stronger social support encourage them to be more trusting. We know that positive social relationships are important to health (Berkman \& Syme, 1979; House, Robbins, \& Metzner, 1982). Religious teaching and social interaction with similarly minded individuals are likely to encourage individuals with more religious involvement, such as religious attendance and church membership, to be more trusting.

\section{Neighborhood predictors}

We consider several neighborhood characteristics as possible predictors of trust: socioeconomic status, inequalities in income, racial/ethnic diversity, linguistic fragmentation, and neighborhood social characteristics.

We expect people living in more impoverished neighborhoods to be less trusting because of less trust promoting resources available to the community, such as income, employment, and stable families. There is evidence that trust is lower in more heterogeneous communities, including communities with more economic inequality and linguistic and racial/ethnic heterogeneity (Putnam, 2007). Racial heterogeneity was shown to lower trust in U.S. cities (Alesina \& La Ferrara, 2002) and in Australian neighborhoods, though, in Australia, linguistic heterogeneity had a stronger association with trust than racial heterogeneity (Leigh, 2006). The relationship between income inequality and trust is less clear (Alesina \& La Ferrara, 2002; Leigh, 2006). The reported decrease in trust among more heterogeneous communities has been attributed to the notion that trust is more prevalent among individuals who are similar (Alesina \& La Ferrara, 2002; Barr \& La Ferrara, 1999; Coleman, 1990; Glaeser, Laibson, Scheinkman, \& Soutter, 2000). It is expected that people of the same racial/ethnic or socioeconomic group or who speak the same language are more likely to trust group members because of familiarity, ease of communication, and common values and attitudes.

Additional neighborhood social characteristics likely to be associated with residents' trust include: residential stability, collective efficacy, and public disorder. Residential stability is expected to promote trust because residents can develop longer term, trust promoting, interactions in more stable neighborhoods (Alesina \& La Ferrara, 2002; Coleman, 1990). Collective efficacy at the neighborhood level depends on the willingness of residents to intervene for the common good (Sampson et al., 1997). The key causal mechanism is social control enacted under conditions of social trust. Thus, collective efficacy can be used as a proxy for the average level of trust in the community, which is possibly an important predictor of residents' trust because communities where trusting is the norm create an environment that reinforces individual trust. Collective efficacy has been associated with crime, children's well-being, and health outcomes (Sampson, Morenoff, \& Earls, 1999; Sampson et al., 1997). It is also closely linked to social capital, known to influence several health outcomes, including mortality, self-rated health, and obesity to name a few (Kawachi, Kim, Coutts, \& Subramanian, 2004; Kawachi \& Subramanian, 2006; Kim \& Kawachi, 2006; Kim et al., 2006; Lochner, Kawachi, Brennan, \& Buka, 2003; Subramanian, Lochner, \& Kawachi, 2003).

Public disorder is defined by the presence of physical disorder (the presence of litter, graffiti, and vacant houses) and social disorder (drinking in public, selling drugs, and groups hanging out and causing trouble). A disorderly neighborhood is likely to promote suspiciousness and reduce trust. Disorder has been linked to mental and physical health (Aneshensel \& Sucoff, 1996; Balfour \& Kaplan, 2002; Caughy, O’Campo, \& Muntaner, 2003; Cohen et al., 2000; Cutrona, Russell, Hessling, Brown, \& Murry, 2000; Geis \& Ross, 1998; Ross, 2000a, 2000b; Ross, Reynolds, \& Geis, 2000), as well as to crime in public policy (Kelling \& Coles, 1996; Skogan, 1990; Taylor, 2001; Wilson \& Kelling, 1982).

The model for the individual and neighborhood predictors of trust is depicted in Fig. 1 and is applied in this study for several measures of trust.

\section{Methods}

\section{Participants}

Data for this study were drawn from surveys obtained as part of a project exploring social context and health in Texas

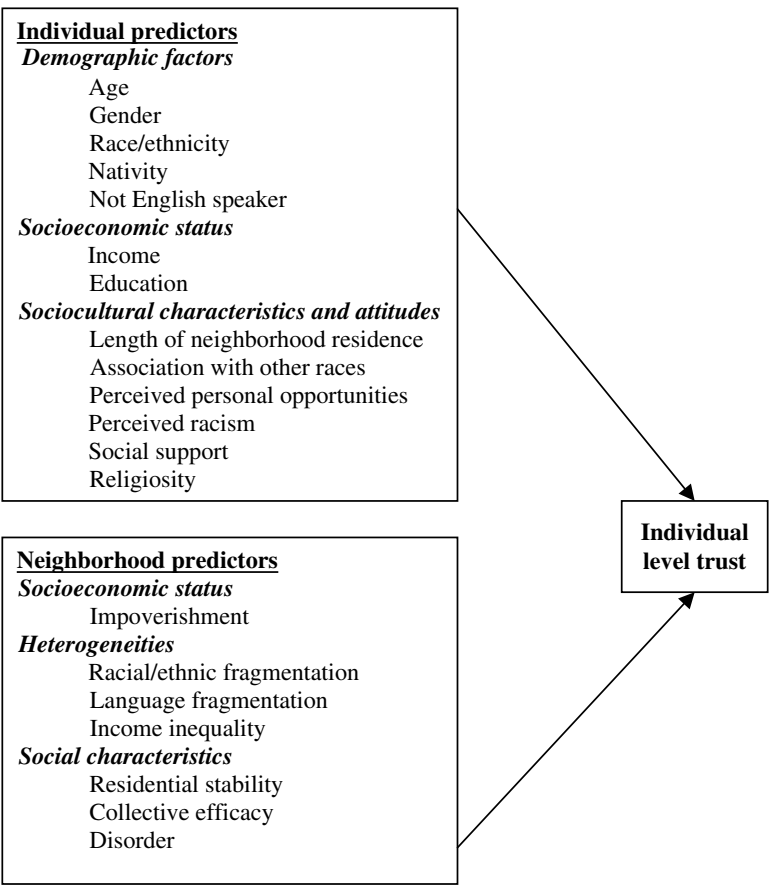

Fig. 1. A model for predictors of trust. 
neighborhoods funded by the Texas Department of Health (Franzini, Caughy, Spears, \& Fernandez Esquer, 2005; Franzini \& Fernandez-Esquer, 2004). The study was conducted in 13 low/medium income communities (11 in the Houston area and 2 in the Lower Rio Grande Valley) between June 2001 and August 2002. Average poverty rate was 28\% and average unemployment rate was $12 \%$. Six communities were predominantly Hispanic (between 78\% and 92\%), three predominantly black (between $82 \%$ and $93 \%$ ), and two predominantly white (62\% and 68\%), one mixed white/ minority (42\% white) and one mixed Hispanic/black (49\% and $43 \%$, respectively). Respondents for the survey were identified in each of the 13 communities using a multistage probability sample of dwellings. The multistage probability sample was drawn in three stages: (1) city blocks were sampled based on population density in each community; (2) dwelling units were sampled within each block; (3) one adult was sampled within each selected dwelling unit. The residences on each block were selected by randomly choosing a house to be interviewed first on each block and continuing interviewing each third house. If a house had no respondent, either because of refusal or because of inability to contact after two calls, the interviewer was instructed to substitute that house with the one next door.

For the purpose of the multilevel analysis, the "neighborhood" was defined as the census block group. Block groups, with an average population size of 1000 people, are the smallest geographic areas for which census information is available. There are several reasons for this approach. First, census block groups are more homogeneous demographically and economically than larger areas and, therefore, social and physical characteristics are also likely to be more homogenous at the block group level than in larger areas (O'Campo, 2003). Second, residents tend to define neighborhoods as a small area proximal to their residence and block groups provide more accurate measurements of neighborhood effects (Grannis, 1998). Third, individual understanding of neighborhood in response to questions on trustworthiness of neighbors or the extent to which they know people is generally equivalent to the level of street, road or block (Campbell, 1999).

In the sample of 3203 respondents, 3171 resided in a block group with at least 5 respondents (Raudenbush \& Sampson, 1999). This study uses responses from the 1745 individuals who were identified as of Mexican-origin based on questions on race/ethnicity and country of birth and who resided in a block group with at least five respondents. The Mexican-origin sample was clustered in 79 block groups. See Franzini \& Fernandez-Esquer (2004) for a full description of the study.

\section{Measures}

\section{Individual level measures}

General social trust was obtained using the question from the General Social Survey: "Do you think that most people can be trusted - or you can't be too careful about dealing with people" which has been extensively used (Alesina \& La Ferrara, 2002; Kawachi \& Berkman, 2000; Leigh, 2006). Questions on trust addressed several distinct types of trust, including general trust (trust in people in general, people in the U.S., and people in Mexico), localized trust (trust in people in the neighborhood and trust in people of same racial/ethnic group), trust in those who are part of daily life (trust in bank personnel and store clerks), and trust in institutions (trust in the police and immigration agencies). The questions were used to create a binary indicator of each aspect of trust indicating whether or not the respondent reports this type of trust. We asked about trust in people in the U.S. and people in Mexico to compare trust in the country of residence and the country of origin. An experiment performed by Glaeser et al. (2000) indicated that the General Social Survey question on trust identifies those who act in a trustworthy manner, rather than those who trust others. However, we use the question as a measure of trust in others as has the recent health literature on trust (Kim et al., 2006; Lochner et al., 2003).

The measurement of self-rated health (ordinal variable) was captured by a single question "In general, would you say your health is ...?" that is rated on a five-point Likert scale from poor to excellent. Self-rated health is a powerful and reliable predictor of clinical outcome and mortality, even 10 years after the initial self-rating (Fayers \& Sprangers, 2002; Idler \& Angel, 1990).

Demographic characteristics included age, gender, nativity, and language use. Age was reported in years and gender as a dummy variable. Nativity was measured by asking if the respondent was U.S. or foreign born and the country of birth. Language use was obtained using questions modified from the ARSMA (Acculturation Rating Scale for Mexican-Americans) scale, which measures acculturation in Mexican-Americans (Cuellar, Arnold, \& Maldonado, 1995; Cuellar, Harris, \& Jasso, 1980). Language use was dichotomized into those who mostly or always speak Spanish at home and mostly or always prefer Spanish music and TV (Spanish speakers) and those who don't (English speakers).

Income (continuous variable) and education (categorical variable) measured socioeconomic status. Family incometo-need ratio was determined by comparing the family's income (15 categories) to the federal poverty line in 2001 based on family size, determined from a complete household roster. Educational attainment was measured in seven categories, from elementary school to advanced degree and including education in the U.S. and in the native country.

The following sociocultural personal characteristics (treated as continuous variables in the analysis) were measured: length of residence in the neighborhood, frequency of association with people of the same race/ ethnicity and with people of different races/ethnicities, perceived personal opportunity (Kluegel \& Smith, 1986), perceived racism (Harrell, 2000), perceived social support measured by number of friends and frequency of contact (Berkman \& Syme, 1979), and religiosity, measured by attendance to religious services and other activities at the place of worship (Strawbridge, Shema, Cohen, Roberts, \& Kaplan, 1998). See Franzini and Fernandez-Esquer (2004) for a fuller description of the scales.

\section{Neighborhood level measures}

An index of neighborhood impoverishment measured neighborhood socioeconomic status. Neighborhood 
impoverishment was a composite score obtained at the block group level from Census 2000 data by z-score standardizing and averaging the neighborhood poverty rate, unemployment rate, vacant housing rate, and proportion of households with children under the age of 5 years which were single-headed (Korbin, Coulton, Chard, Platt-Houston, \& Su, 1998). It was treated as continuous variable in the analyses.

Neighborhood heterogeneities included the degree of income inequality, racial/ethnic heterogeneity, and linguistic heterogeneity computed using Census 2000 data. Income inequality was measured by computing the Gini coefficient for household incomes at the block group level. Racial/ethnic heterogeneity and linguistic heterogeneity were measured by a fragmentation index similar to the Herfindahl index (Alesina, Devleeschauwer, Easterly, Kurlat, \& Wacziarg, 2003; Alesina \& La Ferrara, 2002; Leigh, 2006). The Herfindahl index is a commonly accepted measure of market concentration used in industry. The fragmentation index in a given block group measures the chance that two randomly selected individuals are in different racial/ethnic or linguistic groups. The fragmentation index was computed as:

Fragmentation $_{j}=1-\sum_{k} S_{k j}^{2}$

where $j$ represents the block group and $S_{k j}$ represents the share of group $k$ in block group $j$. In computing the racial/ ethnic fragmentation index, $S_{k j}(k=1,4)$ represents the share of each racial/ethnic group in neighborhood $j$. Using Census 2000 data, we identified the following racial/ethnic groups: non-Hispanic White, non-Hispanic Black, Hispanic, and other race/ethnicity. In computing the linguistic fragmentation index, $S_{k j}(k=1,2)$ represents the share of English speakers and non-English speakers in neighborhood $j$. Non-English speakers were identified in the census as those speaking English "not at all" or "not well".

The following neighborhood social characteristics were measured: residential stability (the percentage of neighborhood residents who have lived at the current residence at least 5 years); collective efficacy, consisting of social cohesion (closeness, common values, and trust and helpfulness at the community level) and informal social control (willingness to intervening if children misbehave or skip school or if a community problem arises) (Sampson et al., 1997); and public disorder, consisting of physical disorder (the presence of litter, graffiti, and vacant houses) and social disorder (drinking in public, selling drugs, and groups hanging out and causing trouble) (Earls, 1999). Questions about the neighborhood were asked of respondents and aggregated at the block group level to obtain neighborhood level measures. All variables were treated as continuous variables in the analyses. See Franzini et al. (2005) for a fuller description of the scales.

\section{Statistical analysis}

First, descriptive statistics for individual and neighborhood variables were computed. Scales representing sociocultural personal characteristics and attitudes and neighborhood social characteristics were rescaled to be between 0 and 1 for easier comparison with higher scores indicating more (for example a score of 0.70 for perceived racism indicates more perceived racism than a score of 0.40). Second, chi-square tests compared proportion trusting for different measures of trust and were used to test for correlations between trust measures. Third, ordinal logistic regression investigated the impact of several measures of trust on self-rated health controlling for individual sociodemographic factors and allowing for clustering at the block group level. Finally, regressions of measures of trust on individual and neighborhood characteristics were conducted by running probit regressions with corrections for clustering at the block group level. We used the xt commands in Stata (STATA Corporation, 2007) that allow for the multilevel nature of the data. Individual level variables are entered as level 1 variables and neighborhood level variables are entered as level 2 variables. Marginal probit coefficients calculated at the means are reported. The income-to-need ratio variable is entered as $\log$ in the models. Non-linear associations of trust with education were modeled using education as a categorical variable. Non-linear associations of trust with neighborhood impoverishment were also investigated but are not reported because they had worse fit and squared terms were not significant.

\section{Results}

\section{Sample description}

The Mexican-origin sample is described in Table 1. Descriptive statistics were computed for all observations available for each variable. The sample was predominately female, foreign born, Spanish speaking, and had low education and income. On average, residents lived in the neighborhood 2-5 years and were more likely to associate with people of their own race/ethnicity. The majority of respondents perceived personal opportunities, had good social support, and was religious. Scale items not shown in the table indicate that $15 \%$ had personally experienced some racial/ethnic prejudice in their life time and $29 \%$ thought that Hispanics are regarded negatively in the U.S.

Income inequality, racial/ethnic fragmentation, and linguistic fragmentation in the sampled 79 block groups were similar to the averages reported for the U.S. and Australia (Alesina \& La Ferrara, 2002; Leigh, 2006). The sample neighborhoods were mainly poor with average poverty rate of $23 \%$ and unemployment rate of $12 \%$. On average, residents have lived at the current residence for more than 5 years.

\section{Correlations between trust measures}

The percentage of respondents who trust is reported in Table 2 for all measures of trust. On average, 19\% of respondents trusted people in general. Similar percentages trusted people in the U.S. and Mexico. Overall, general trust (trust in people in general and trust in people in the U.S. and in Mexico) tended to be less common than localized trust (trust in people in the neighborhood or of the same 
Table 1

Mexican-origin sample description: individual and neighborhood characteristics

\begin{tabular}{|c|c|c|c|}
\hline Variable and range & Number & $\begin{array}{l}\text { Mean } \\
\text { or } \%\end{array}$ & $\begin{array}{l}\text { Standard } \\
\text { deviation }\end{array}$ \\
\hline \multicolumn{4}{|l|}{ Individual variables } \\
\hline Age in years (18-94) & 1735 & 39.27 & 15.16 \\
\hline Female $(0-1)$ & 1741 & $74 \%$ & - \\
\hline Foreign born $(0-1)$ & 1736 & $68 \%$ & - \\
\hline Spanish speaking $(0-1)$ & 1686 & $56 \%$ & - \\
\hline Education $(1-7)^{\mathrm{a}}$ & 1708 & 2.61 & 1.57 \\
\hline Income-to-need ratio $(0.06-11.06)$ & 1581 & 1.24 & 1.12 \\
\hline Time lived in neighborhood $(1-7)^{b}$ & 1738 & 3.74 & 1.70 \\
\hline $\begin{array}{l}\text { Associate with other } \\
\text { race/ethnicities }(1-5)^{c}\end{array}$ & 1622 & 1.84 & 1.06 \\
\hline Perceived personal opportunity $(0-1)$ & 1634 & 0.65 & 0.21 \\
\hline Perceived racism $(0-1)$ & 1663 & 0.26 & 0.16 \\
\hline Social support (0-1) & 1680 & 0.31 & 0.22 \\
\hline Religiosity (0-1) & 1732 & 0.56 & 0.33 \\
\hline \multicolumn{4}{|l|}{ Neighborhood variables } \\
\hline Impoverishment index ( -1.21 to 6.08$)$ & 79 & 0.57 & 1.15 \\
\hline $\begin{array}{l}\text { Racial/ethnic fragmentation } \\
(0.04-0.68)\end{array}$ & 79 & 0.36 & 0.18 \\
\hline Linguistic fragmentation (0.0-0.49) & 79 & 0.25 & 0.16 \\
\hline Gini coefficient $(0.26-0.71)$ & 79 & 0.41 & 0.08 \\
\hline Residential stability (3-82\%) ${ }^{\mathrm{d}}$ & 79 & $52 \%$ & - \\
\hline Collective efficacy (0.46-0.79) & 79 & 0.64 & 0.08 \\
\hline Disorder $(0.01-0.72)$ & 79 & 0.30 & 0.17 \\
\hline
\end{tabular}

a Education: 1 = elementary, 2 =junior high, $3=$ some high school $4=$ high school graduate, $5=$ some college/associate degree, $6=$ college graduate, 7 = advanced degree.

b Time lived in neighborhood: $1=<1$ year, $2=1-2$ years, $3=>2-5$ years, $4=>5-10$ years, $5=>10-20$ years, $6=>20-30$ years, $7=>30$ years.

c Associate with other race/ethnicity: $1=$ almost exclusively with same, $2=$ mostly with same, $3=$ equally with same and other, $4=$ mostly with other, 5 = almost exclusively with other.

d \% At current residence for 5 or more years.

racial/ethnic group). Trust in those in the same racial/ethnic group and trust in people in the neighborhood were more common than general trust $(P<0.01)$. Trust in people in the neighborhood was more frequently reported than trust in the same racial/ethnic group $(P<0.01)$. Respondents reported trusting institutions or those representing institutions (bank/store personnel, police, and immigration agencies) more than other people (general and localized trust). Not surprisingly in a population with a high immigrant concentration, the least frequently reported institutional trust was trust in immigration agencies. The proportion reporting institutional trust in this largely disadvantaged population was greatest with respect to trust in the police. All measures of trust were positively correlated using the chi-square test.

\section{Trust and self-rated health}

In our sample, trust had a strong association with selfrated health. All measures of trust, except trust in bank/ store personnel, were significantly and positively associated with self-rated health, after controlling for basic sociodemographic factors (Table 3 ).

\section{Predictors of trust}

The multivariate probit models for general trust (trust in people in general, people in the U.S., and people in Mexico) are reported in Table 4. The percentage of total variance contributed by the neighborhood level variance component was significant in two of the three models, indicating that trust did indeed vary at the neighborhood level. Females were less likely to report general trust. Older and more educated respondents were more likely to trust people in the U.S. Foreign born were somewhat more likely to report trust in people in Mexico. Speaking Spanish, income, time in the neighborhood, and all sociocultural personal characteristics were not associated with general trust levels. Trust in people in general was positively associated with collective efficacy and weakly ( $P$ value $<0.10)$ negatively associated with income inequality. Trust in people in the U.S. and in Mexico was reported less frequently in neighborhoods with more linguistic fragmentation. Racial/ethnic diversity and impoverishment were not associated with generalized trust.

Table 5 reports the predictors of localized trust. Education was consistently positively associated with localized trust and female respondents reported less trust in those of the same race/ethnicity, but other sociodemographic and sociocultural personal characteristics were not associated with localized trust. Respondents in neighborhoods with more income inequality and linguistic fragmentation reported less localized trust. Collective efficacy was positively associated with trust in neighbors. Racial/ethnic diversity and impoverishment were not associated with localized trust.

\section{Table 2}

Descriptive statistics for trust measures in the Mexican-origin sample: percent trusting and chi-square tests

\begin{tabular}{|c|c|c|c|c|c|c|c|c|c|}
\hline \multirow[t]{2}{*}{ Trust: } & \multirow[t]{2}{*}{$N$} & \multirow[t]{2}{*}{ \% Who trust } & \multicolumn{7}{|c|}{ Chi-square test } \\
\hline & & & $\begin{array}{l}\text { People in } \\
\text { general }\end{array}$ & $\begin{array}{l}\text { People } \\
\text { in U.S. }\end{array}$ & $\begin{array}{l}\text { People in } \\
\text { Mexico }\end{array}$ & $\begin{array}{l}\text { People in } \\
\text { neighborhood }\end{array}$ & $\begin{array}{l}\text { People of same } \\
\text { racial/ethnic group }\end{array}$ & Police & $\begin{array}{l}\text { Bank/store } \\
\text { personnel }\end{array}$ \\
\hline People in general & 1628 & 19 & & & & & & & \\
\hline People in U.S. & 1713 & 21 & 597.9 & & & & & & \\
\hline People in Mexico & 1713 & 23 & 368.6 & 815.1 & & & & & \\
\hline People in neighborhood & 1720 & 31 & 410.8 & 508.0 & 470.6 & & & & \\
\hline People of same racial/ethnic group & 1703 & 23 & 413.8 & 731.7 & 631.5 & 699.5 & & & \\
\hline Police & 1709 & 45 & 209.9 & 349.9 & 225.2 & 445.6 & 341.4 & & \\
\hline Bank/store personnel & 1702 & 35 & 282.3 & 441.4 & 296.2 & 423.9 & 438.8 & 657.3 & \\
\hline Immigration agency & 1665 & 29 & 200.9 & 280.7 & 210.7 & 314.9 & 296.8 & 622.1 & 661.2 \\
\hline
\end{tabular}

All chi-square tests are significant at the $0.001 \%$ level. 
Table 3

Self-rated health and trust: odds ratios for trust measures from the ordinal logistic regression with self-rated health as dependent variable

\begin{tabular}{llr}
\hline Measure of trust & Odds ratio $^{\mathrm{a}}$ & $P$ value \\
\hline Trust people in general & 1.62 & $<0.01$ \\
Trust people in the U.S. & 1.71 & $<0.01$ \\
Trust people in the Mexico & 1.71 & $<0.01$ \\
Trust people in the neighborhood & 1.40 & $<0.01$ \\
Trust people of the same race/ethnicity & 1.75 & $<0.01$ \\
Trust in the police & 1.25 & 0.03 \\
Trust in bank/store personnel & 1.26 & 0.07 \\
Trust in immigration agencies & 1.44 & $<0.01$
\end{tabular}

a Adjusted for age, gender, nativity, Spanish speaker, education, and log (income-to-need ratio).

The predictors of trust in institutions are reported in Table 6. As for general and localized trust, education was positively associated with trust in institutions. The sociocultural personal characteristics correlated with institutional trust varied by institution. Trust in the police was positively associated with perceptions of personal opportunity. Respondents who associate more with other races/ ethnicities were more likely to trust bank/store personnel. Trust in immigration agencies was positively influenced by associating with other races/ethnicities, perceiving personal opportunities, and social support. Of the neighborhood characteristics, collective efficacy was positively associated with trust in all institutions. Linguistic fragmentation was negatively correlated with trust in the police and weakly $(P$ value $<0.10)$ with trust in immigration agencies. Racial/ethnic fragmentation, income inequality, and impoverishment had no association with institutional trust.

\section{Discussion}

All measures of trust were important predictors of selfrated health in our sample of Mexican-origin individuals living in low-income neighborhoods. This is consistent with the literature relating trust to better health outcomes (Kawachi \& Berkman, 2000; Kim \& Kawachi, 2006; Kim et al., 2006; Subramanian et al., 2002). Also, consistent with the literature, we found that trust levels in this low-income Mexican sample were indeed lower than in the general population. Only $19 \%$ of respondents reported trusting people in general, compared to $40 \%$ of the U.S. general population (Alesina \& La Ferrara, 2002) and 58\% of the Australian population (Leigh, 2006). Since predictors of trust in minority populations have not been investigated in the literature, we filled this gap by investigating the predictors of trust in this low-income Mexican-American sample.

Table 4

Predictors of generalized trust in the Mexican-origin sample

\begin{tabular}{|c|c|c|c|c|c|c|}
\hline \multirow[t]{2}{*}{ Independent variable } & \multicolumn{2}{|c|}{ Trust in people in general } & \multicolumn{2}{|c|}{ Trust in people in the U.S. } & \multicolumn{2}{|c|}{ Trust in people in Mexico } \\
\hline & Coefficient & $P$ value & Coefficient & $P$ value & Coefficient & $P$ value \\
\hline \multicolumn{7}{|l|}{ Individual level } \\
\hline Age & 0.01 & 0.03 & 0.01 & 0.04 & 0.00 & 0.93 \\
\hline Female & -0.23 & 0.02 & -0.24 & 0.02 & -0.24 & 0.01 \\
\hline Foreign born & 0.11 & 0.36 & 0.02 & 0.84 & 0.20 & 0.05 \\
\hline Spanish speaker & -0.19 & 0.10 & -0.08 & 0.48 & -0.03 & 0.76 \\
\hline Education junior high & 0.00 & 0.98 & 0.12 & 0.37 & 0.15 & 0.23 \\
\hline Education some high school & 0.12 & 0.48 & 0.17 & 0.29 & -0.03 & 0.86 \\
\hline Education high school graduate & 0.11 & 0.49 & 0.19 & 0.22 & 0.09 & 0.54 \\
\hline Education some college & 0.19 & 0.31 & 0.39 & 0.03 & 0.17 & 0.34 \\
\hline Education college graduate & 0.42 & 0.09 & 0.26 & 0.29 & 0.36 & 0.13 \\
\hline Education advanced degree & 0.55 & 0.12 & 0.49 & 0.13 & 0.19 & 0.56 \\
\hline Log (income-to-need ratio) & 0.02 & 0.76 & -0.04 & 0.46 & 0.00 & 0.97 \\
\hline Time in neighborhood. & 0.00 & 0.93 & -0.02 & 0.56 & -0.02 & 0.48 \\
\hline Associate with other race/ethnicity & -0.05 & 0.27 & -0.02 & 0.69 & -0.03 & 0.51 \\
\hline Personal opportunity & 0.09 & 0.68 & -0.17 & 0.42 & 0.02 & 0.93 \\
\hline Perceived racism & -0.38 & 0.21 & 0.06 & 0.83 & 0.36 & 0.20 \\
\hline Social support & 0.33 & 0.10 & -0.06 & 0.77 & 0.12 & 0.56 \\
\hline Religiosity & 0.09 & 0.56 & 0.06 & 0.66 & 0.02 & 0.88 \\
\hline \multicolumn{7}{|l|}{ Neighborhood level } \\
\hline Impoverishment & $<0.01$ & 1.00 & -0.01 & 0.87 & -0.05 & 0.57 \\
\hline Race/ethnic fragmentation & 0.67 & 0.20 & 0.57 & 0.32 & 0.23 & 0.69 \\
\hline Gini coefficient & -2.05 & 0.08 & -1.91 & 0.16 & -1.13 & 0.41 \\
\hline Linguistic fragmentation & -0.78 & 0.23 & -1.15 & 0.09 & -1.26 & 0.05 \\
\hline Residential stability & -0.10 & 0.85 & -0.48 & 0.43 & -0.37 & 0.55 \\
\hline Collective efficacy & 1.92 & 0.05 & 0.89 & 0.39 & 0.75 & 0.48 \\
\hline Disorder & 0.09 & 0.83 & 0.31 & 0.54 & 0.32 & 0.53 \\
\hline Level 2 standard deviation & 0.18 & & 0.30 & & 0.30 & \\
\hline Rho & 0.03 & 0.22 & 0.08 & $<0.01$ & 0.08 & 0.01 \\
\hline$N$ & 1167 & & 1219 & & 1216 & \\
\hline Number of groups & 71 & & 71 & & 71 & \\
\hline Log likelihood & -528.1 & & -585.56 & & -613.06 & \\
\hline
\end{tabular}

Rho is the portion of total variance contributed by the level 2 variance component.

Statistical significance at the $5 \%$ level is indicated in bold; statistical significance at the $10 \%$ level is indicated in italic-bold. 
Table 5

Predictors of localized trust in the Mexican-origin sample

\begin{tabular}{|c|c|c|c|c|}
\hline \multirow[t]{2}{*}{ Independent variable: } & \multicolumn{2}{|c|}{$\begin{array}{l}\text { Trust in people } \\
\text { in neighborhood }\end{array}$} & \multicolumn{2}{|c|}{$\begin{array}{l}\text { Trust in people of } \\
\text { same race/ethnicity }\end{array}$} \\
\hline & Coefficient & $P$ value & Coefficient & $P$ value \\
\hline \multicolumn{5}{|l|}{ Individual level } \\
\hline Age & $<0.01$ & 0.16 & 0.01 & 0.15 \\
\hline Female & -0.11 & 0.23 & -0.27 & 0.01 \\
\hline Foreign born & 0.10 & 0.35 & 0.15 & 0.20 \\
\hline Spanish speaker & -0.10 & 0.33 & -0.07 & 0.49 \\
\hline Education junior high & 0.16 & 0.17 & 0.27 & 0.03 \\
\hline Education some high school & 0.05 & 0.75 & 0.20 & 0.22 \\
\hline $\begin{array}{l}\text { Education high school } \\
\text { graduate }\end{array}$ & 0.32 & 0.03 & 0.35 & 0.03 \\
\hline Education some college & 0.26 & 0.13 & 0.30 & 0.09 \\
\hline Education college graduate & 0.60 & 0.01 & 0.35 & 0.17 \\
\hline Education advanced degree & 1.01 & $<0.01$ & 0.57 & 0.09 \\
\hline Log (income-to-need ratio) & 0.01 & 0.89 & 0.01 & 0.84 \\
\hline Time in neighborhood & 0.04 & 0.19 & 0.02 & 0.51 \\
\hline $\begin{array}{l}\text { Associate with other } \\
\text { race/ethnicity }\end{array}$ & 0.05 & 0.24 & -0.01 & 0.87 \\
\hline Personal opportunity & -0.22 & 0.27 & 0.02 & 0.93 \\
\hline Perceived racism & $<0.01$ & 1.00 & -0.10 & 0.73 \\
\hline Social support & 0.08 & 0.66 & 0.07 & 0.73 \\
\hline Religiosity & -0.02 & 0.88 & 0.11 & 0.44 \\
\hline \multicolumn{5}{|l|}{ Neighborhood level } \\
\hline Impoverishment & 0.09 & 0.17 & 0.07 & 0.43 \\
\hline Race/ethnic fragmentation & 0.03 & 0.95 & 0.32 & 0.57 \\
\hline Gini coefficient & -2.87 & $<0.01$ & -3.82 & $<0.01$ \\
\hline Linguistic fragmentation & -1.62 & $<0.01$ & -1.52 & 0.02 \\
\hline Residential stability & -0.48 & 0.30 & -0.58 & 0.34 \\
\hline Collective efficacy & 3.50 & $<0.01$ & 1.47 & 0.16 \\
\hline Disorder & 0.18 & 0.62 & 0.64 & 0.19 \\
\hline Level 2 standard deviation & 0.13 & & 0.29 & \\
\hline Rho & 0.02 & 0.21 & 0.07 & $<0.01$ \\
\hline$N$ & 1218 & & 1212 & \\
\hline Number of groups & 72 & & 70 & \\
\hline Log likelihood & -687.20 & & -595.83 & \\
\hline
\end{tabular}

Rho is the portion of total variance contributed by the level 2 variance component.

Statistical significance at the $5 \%$ level is indicated in bold; statistical significance at the $10 \%$ level is indicated in italic-bold.

Because we sampled from a low-income Mexican group, the educational and income levels were low with $70 \%$ of respondents with less than a high school education and half the sample below the poverty line. Despite this lack of variability, education, but not income and sociocultural characteristics, was a strong predictor of trust.

Mexican-American respondents tended to trust other Mexican-Americans more than people in general, supporting the notion that people trust more those who are similar to themselves (Alesina \& La Ferrara, 2002; Barr \& La Ferrara, 1999; Coleman, 1990). However, Mexican-American respondents trusted their neighbors even more than they trusted other Mexican-Americans. These results suggest that trust is higher in those with whom there is likely to be a personal acquaintance, like those living in the neighborhood, than in those who belong to a common social group, like members of the same racial/ethnic group. Trust in neighbors was significantly lower in neighborhoods with economic disparities and linguistic fragmentation, suggesting that economic inequalities and the inability to communicate at the neighborhood level discourage trust even among people who live in close proximity and have opportunities for daily contact.

Trust in people of the same race/ethnicity was also negatively correlated with economic disparities and linguistic fragmentation, suggesting that, when making decisions about whom they trust, Mexican-origin respondents consider not only race/ethnicity but also socioeconomic status and language use. Based on the notion that people tend to trust more those they perceive similar to themselves, one possible implication of our results is that Mexican-Americans identify similarity based not only on race/ethnicity, but also on socioeconomic status and language use.

Foreign born respondents, almost all of whom were born in Mexico, seemed more likely than U.S. born respondents to trust people in Mexico, but not less likely to trust people in general or people in the U.S. Speaking Spanish was not associated with trust levels. The result that nativity, but not language, correlates with trust in people in Mexico supports the notion that individuals tend to trust more those they know personally, given that foreign born are likely to have lived or have family in Mexico. Since we have no data on trust levels in Mexico, we cannot investigate how immigration to the U.S. has affected trust, but our results indicate that, overall, immigrants have trust levels (general, localized, and institutional) similar to those of U.S. born respondents.

Racial/ethnic fragmentation was not associated with any measure of trust in our Mexican-American sample. This is in contrast with studies reporting that people in the U.S. were less likely to trust in racially fragmented cities (Alesina \& La Ferrara, 2002; Putnam, 2007). In our Mexican low-income population, the lack of association between racial/ethnic fragmentation and trust suggests that ethnic diversity does not necessarily correlate with lower trust levels. This is an important result because much has been said about racial/ethnic diversity having a negative influence on trust and social capital (Alesina \& La Ferrara, 2002; Putnam, 2007). Putnam (2007) argued that racial/ethnic diversity fosters social isolation. Based on evidence from the U.S., he suggested "in ethnically diverse neighborhoods residents of all races tend to 'hunker down'. Trust (even of one's own race) is lower, altruism and community cooperation rarer, friends fewer." (p. 137 in Putnam, 2007).

Linguistic fragmentation, on the other hand, was a predictor of trust. This finding mirrors results by Leigh (2006) in Australia. It seems that in low-income minority neighborhoods, it is linguistic diversity, and the related difficulties in communication, rather than racial/ethnic diversity that are relevant to trust. In particular, in a more linguistically fragmented neighborhood, trust is lower in all neighborhood level interactions, including trust in neighbors and in the local police. It is also associated with lower trust in those of the same racial/ethnic group, but who may speak a different language. These results suggest that it is the ability to communicate, rather than membership in a common social group such as a racial/ethnic group, that correlates with trust levels in our sample.

Unlike in other studies, neighborhood level socioeconomic status, here measured by impoverishment, was not associated with any measure of trust (Alesina \& La Ferrara, 
Table 6

Predictors of trust in institutions in the Mexican-origin sample

\begin{tabular}{|c|c|c|c|c|c|c|}
\hline \multirow[t]{2}{*}{ Independent variable: } & \multicolumn{2}{|c|}{ Trust in the police } & \multicolumn{2}{|c|}{ Trust in bank/store personnel } & \multicolumn{2}{|c|}{ Trust in immigration agencies } \\
\hline & Coefficient & $P$ value & Coefficient & $P$ value & Coefficient & $P$ value \\
\hline \multicolumn{7}{|l|}{ Individual level } \\
\hline Age & $<0.01$ & 0.16 & $<0.01$ & 0.19 & 0.01 & 0.02 \\
\hline Female & -0.07 & 0.43 & -0.14 & 0.14 & 0.05 & 0.59 \\
\hline Foreign born & 0.07 & 0.50 & 0.07 & 0.51 & -0.04 & 0.74 \\
\hline Spanish speaker & 0.04 & 0.64 & -0.15 & 0.14 & 0.05 & 0.62 \\
\hline Education junior high & 0.21 & 0.05 & 0.07 & 0.56 & 0.20 & 0.11 \\
\hline Education some high school & 0.25 & 0.07 & 0.28 & 0.06 & 0.21 & 0.17 \\
\hline Education high school graduate & 0.35 & 0.01 & 0.22 & 0.13 & 0.30 & 0.05 \\
\hline Education some college & 0.28 & 0.08 & 0.37 & 0.03 & 0.35 & 0.04 \\
\hline Education college graduate & 0.29 & 0.19 & 0.16 & 0.50 & 0.22 & 0.35 \\
\hline Education advanced degree & 0.66 & 0.03 & 0.67 & 0.03 & 0.46 & 0.16 \\
\hline Log (income-to-need ratio) & -0.08 & 0.10 & -0.03 & 0.64 & -0.04 & 0.50 \\
\hline Time in neighborhood. & 0.01 & 0.71 & 0.02 & 0.41 & 0.03 & 0.33 \\
\hline Associate with other race/ethnicity & 0.07 & 0.05 & 0.11 & 0.01 & 0.16 & $<0.01$ \\
\hline Personal opportunity & 0.37 & 0.05 & 0.14 & 0.47 & 0.65 & $<0.01$ \\
\hline Perceived racism & 0.09 & 0.73 & -0.18 & 0.51 & -0.02 & 0.95 \\
\hline Social support & -0.10 & 0.58 & 0.19 & 0.31 & 0.45 & 0.02 \\
\hline Religiosity & -0.04 & 0.75 & -0.01 & 0.91 & -0.08 & 0.56 \\
\hline \multicolumn{7}{|l|}{ Neighborhood level } \\
\hline Impoverishment & -0.05 & 0.32 & -0.04 & 0.67 & -0.07 & 0.42 \\
\hline Race/ethnic fragmentation & -0.65 & 0.10 & 0.06 & 0.92 & -0.26 & 0.63 \\
\hline Gini coefficient & 1.35 & -0.09 & -1.50 & 0.26 & 0.02 & 0.99 \\
\hline Linguistic fragmentation & -1.72 & $<0.01$ & -0.73 & 0.26 & -1.09 & 0.09 \\
\hline Residential stability & -0.59 & 0.12 & -0.56 & 0.34 & -0.13 & 0.82 \\
\hline Collective efficacy & 4.00 & $<0.01$ & 2.11 & 0.04 & 2.06 & 0.04 \\
\hline Disorder & 0.50 & 0.08 & 0.23 & 0.63 & 0.21 & 0.65 \\
\hline Level 2 standard deviation & $<0.01$ & & 0.30 & & 0.25 & \\
\hline Rho & $<0.01$ & 0.49 & 0.08 & $<0.01$ & 0.06 & $<0.01$ \\
\hline$N$ & 1214 & & 1212 & & 1185 & \\
\hline Number of groups & 71 & & 71 & & 70 & \\
\hline Log likelihood & -790.42 & & -716.82 & & -647.66 & \\
\hline
\end{tabular}

Rho is the portion of total variance contributed by the level 2 variance component.

Statistical significance at the $5 \%$ level is indicated in bold; statistical significance at the $10 \%$ level is indicated in italic-bold.

2002; Leigh, 2006). But the neighborhood level distribution of income was negatively associated with localized trust, suggesting that income inequality at the local level may discourage trust and community cohesiveness. In our sample of disadvantaged minority communities, trust in people in general was only weakly correlated with income inequality, a result in contrast to what is reported for the general U.S. population (Alesina \& La Ferrara, 2002).

In our Mexican-American sample, there was a strong positive association between collective efficacy, reflecting community level trust, and respondents' trust in people in general, in neighbors, in the police, and in personnel in local stores. Collective efficacy, on the other hand, was not associated with trust in members of the same racial/ethnic group. Our results support the notion that neighborhoods where trusting is the norm create an environment that reinforces individual trust and that individuals surrounded by trusting people are more willing to trust.

These findings have important policy implications. Unlike Alesina and La Ferrara (2002) and Putnam (2007), who implied that lower trust levels are inevitable in diverse communities because people tend to trust more those who are like themselves, our results are encouraging for the development of policies and interventions aimed at promoting trust in all communities. The finding in this study that people tend to trust more neighbors with whom there is likely to be a personal acquaintance than those who belong to some common social group suggests that encouraging personal acquaintance and social interaction among neighbors may have a positive influence on trust levels even in diverse communities. Furthermore, the finding that racial/ethnic diversity is not associated with any trust measure but that language fragmentation is negatively associated with general and localized trust suggests that intervention aimed at improving communications, including language skills, have the potential to raise trust levels in diverse communities. Finally, the finding that collective efficacy is associated with several measures of trust supports the notion that trust may be encouraged in disadvantaged neighborhoods by programs aimed at promoting collective efficacy.

\section{Limitations}

Because the sample in this study was taken from lowincome and minority communities in the Houston area and the Rio Grande Valley in Texas and had an over-representation of women, it is not representative of the MexicanAmericans in Texas or in the U.S., thereby limiting the generalizability of the results. The over-representation of women is not unusual in surveys conducted face-to-face in the community given that more women are likely to be at 
home at the time of the interview. A limitation of this study is that, because of the cross-sectional nature of the data, no causality can be inferred in these results. A longitudinal study would be needed to discuss causality. Furthermore, there may be some circularity in the relationship between trust in people in the neighborhood and collective efficacy because one of the 10 items in the collective efficacy scale asks respondents to agree or disagree with the statement "people in this neighborhood can be trusted".

\section{Conclusions}

In our sample of low-income Mexican-origin individuals, linguistic fragmentation, but not racial/ethnic diversity, correlated with trust. Ease of communication seems to be more important than racial/ethnic homogeneity in encouraging interpersonal trust at the neighborhood level. This study suggests that Mexican-American individuals tend to trust more neighbors with whom there is likely to be a personal acquaintance than those who belong to the same racial/ethnic group. Furthermore, while the results of this study support that people tend to trust more those who are like themselves, the identification of who is more alike is not based exclusively on racial/ethnic identity but is a complex process based also on linguistic and socioeconomic similarities.

The findings in this study suggest that racially/ethnically diverse neighborhoods need not have lower trust levels with negative consequences on residents' well-being. It is possible that neighborhood level interventions, focusing on encouraging social interaction and communication in racially/ethnically and linguistically diverse communities, could be developed with the aim of promoting trust. Through increased social integration among residents, diverse communities may be able to reach higher levels of cooperation and collaboration, contributing to positive health outcomes.

\section{References}

Alesina, A., Devleeschauwer, A., Easterly, W., Kurlat, S., \& Wacziarg, R (2003). Fractionalization. Journal of Economic Growth, 8(2), 155-194.

Alesina, A., \& La Ferrara, E. (2002). Who trusts others? Journal of Public Economics, 85, 207-234.

Aneshensel, C., \& Sucoff, C. (1996). The neighborhood context of adolescent mental health. Journal of Health $\mathcal{E}$ 'Social Behavior, 37, 293-310.

Balfour, J. L., \& Kaplan, G. A. (2002). Neighborhood environment and loss of physical function in older adults: evidence from the Alameda County Study [Comment]. American Journal of Epidemiology, 155(6), 507-515.

Barr, A., \& La Ferrara, E. (1999). Familiarity and trust: An experimental investigation [CSAE Working Paper]. University of Oxford.

Berkman, L., \& Syme, L. (1979). Social networks, host resistance, and mortality: a nine-year follow-up study of Alameda county residents. American Journal of Epidemiology, 109, 186-204.

Campbell, C. (1999). Social capital and health. London: Health Education Authority.

Carlson, P. (2004). The European health divide: a matter of financial or social capital? Social Science E' Medicine, 59(9), 1985-1992.

Caughy, M. O., O'Campo, P. J., \& Muntaner, C. (2003). When being alone might be better: neighborhood poverty, social capital, and child mental health. Social Science \& Medicine, 57(2), 227-237.

Cohen, D., Inagami, S., \& Finch, B. (2008). The built environment and collective efficacy. Health E' Place, 14(2), 198-208.

Cohen, D., Spear, S., Scribner, R., Kissinger, P., Mason, K., \& Wildgen, J. (2000). "Broken windows" and the risk of gonorrhea. American Journal of Public Health, 90(2), 230-236.
Coleman, J. (1990). Foundations of social theory. Cambridge, MA: Harvard University Press.

Cook, K. (2001). Trust in society. New York: Russell Sage Foundation.

Cuellar, I., Arnold, B., \& Maldonado, R. (1995). Acculturation Rating Scale for Mexican Americans-II: a revision of the original ARSMA Scale. Hispanic Journal of Behavioral Sciences, 17(3), 275-304.

Cuellar, I., Harris, L., \& Jasso, R. (1980). An acculturation scale for Mexican American normal and clinical populations. Hispanic Journal of Behavioral Sciences, 2(3), 199-217.

Cutrona, C., Russell, D., Hessling, R., Brown, P., \& Murry, V. (2000). Direct and moderating effects of community context on the psychological well-being of African American women. Journal of Personality and Social Psychology, 79, 1088-1101.

Drukker, M., Buka, S. L., Kaplan, C., McKenzie, K., \& Van Os, J. (2005). Social capital and young adolescents' perceived health in different sociocultural settings. Social Science $\mathcal{E}$ Medicine, 61(1), 185-198.

Earls, F. (1999). Project on human development in Chicago neighborhoods: Community survey. Ann Arbor, Michigan: Harvard Medical School.

Fayers, P. M., \& Sprangers, M. A. (2002). Understanding self-rated health. Lancet, 359(9302), 187-188.

Franzini, L., Caughy, M., Spears, W., \& Fernandez Esquer, M. E. (2005). Neighborhood economic conditions, social processes, and self-rated health in low-income neighborhoods in Texas: a multilevel latent variables model. Social Science \& Medicine, 61(6), 1135-1150.

Franzini, L., \& Fernandez-Esquer, M. (2004). Socioeconomic, cultural, and personal influences on health outcomes in low income Mexican-origin individuals in Texas. Social Science $\mathcal{E}$ Medicine, 59, 1629-1646.

Geis, K., \& Ross, C. (1998). A new look at urban alienation: the effect of neighborhood disorder on perceived powerlessness. Social Psychology Quarterly, 61, 232-246.

Glaeser, E., Laibson, D., Scheinkman, J., \& Soutter, C. (August 2000). What is social capital? Quarterly Journal of Economics.

Grannis, R. (1998). The importance of trivial streets: residential streets and residential segregation. American Journal of Sociology, 103, 1530-1564.

Hardin, R. (2002). Trust and trustworthiness. New York: Russell Sage Foundation.

Harrell, S. P. (2000). A multidimensional conceptualization of racismrelated stress: implications for the well-being of people of color. American Journal of Orthopsychiatry, 70(1), 42-57.

House, J. S., Robbins, C., \& Metzner, H. L. (1982). The association of social relationships and activities with mortality: prospective evidence from the Tecumseh community health study. American Journal of Epidemiology, 116, 123-140.

Idler, E. L., \& Angel, R. J. (1990). Self-rated health and mortality in the NHANES-I Epidemiologic Follow-up Study. American Journal of Public Health, 80(4), 446-452.

Kavanagh, A. M., Turrell, G., \& Subramanian, S. V. (2006). Does area-based social capital matter for the health of Australians? A multilevel analysis of self-rated health in Tasmania [See comment]. International Journal of Epidemiology, 35(3), 607-613.

Kawachi, I., \& Berkman, L. (2000). Social cohesion, social capital, and health. In L. F. Berkman, \& I. Kawachi (Eds.), Social epidemiology. New York: Oxford University Press.

Kawachi, I., Kennedy, B. P., Lochner, K., \& ProthrowStith, D. (1997). Social capital, income inequality, and mortality. American Journal of Public Health, 87(9), 1491-1498.

Kawachi, I., Kim, D., Coutts, A., \& Subramanian, S. V. (2004). Commentary: reconciling the three accounts of social capital [Comment]. International Journal of Epidemiology, 33(4), 682-690.

Kawachi, I., \& Subramanian, S. V. (2006). Measuring and modeling the social and geographic context of trauma: a multilevel modeling approach. Journal of Traumatic Stress, 19(2), 195-203.

Kelling, G. L., \& Coles, C. M. (1996). Fixing broken windows: Restoring order and reducing crime in our communities. New York: Free Press.

Kim, D., \& Kawachi, I. (2006). A multilevel analysis of key forms of community- and individual-level social capital as predictors of selfrated health in the United States. Journal of Urban Health, 83(5), 813-826.

Kim, D., Subramanian, S. V., Gortmaker, S. L., \& Kawachi, I. (2006). US state- and county-level social capital in relation to obesity and physical inactivity: a multilevel, multivariable analysis. Social Science E Medicine, 63(4), 1045-1059.

Kluegel, J., \& Smith, E. (1986). Beliefs about inequality. New York, NY: Aldine de Gruyter.

Korbin, J. E., Coulton, C. J., Chard, S., Platt-Houston, C., \& Su, M. (1998). Impoverishment and child maltreatment in African American and European American neighborhoods. Development \& Psychopathology, $10(2), 215-233$. 
Leigh, A. (2006). Trust, inequality and ethnic heterogeneity. The Economic Record, 82(258), 268-280.

Lindstrom, C., \& Lindstrom, M. (2006). "Social capital," GNP per capita, relative income, and health: an ecological study of 23 countries. International Journal of Health Services, 36(4), 679-696.

Lochner, K. A., Kawachi, I., Brennan, R. T., \& Buka, S. L. (2003). Social capital and neighborhood mortality rates in Chicago. Social Science $\mathcal{E}$ Medicine, 56(8), 1797-1805.

Mellor, J. M., \& Milyo, J. (2005). State social capital and individual health status. Journal of Health Politics, Policy E Law, 30(6), 1101-1130.

Nummela, O., Sulander, T., Rahkonen, O., Karisto, A., \& Uutela, A. (2008). Social participation, trust and self-rated health: a study among ageing people in urban, semi-urban and rural settings. Health \& Place, 14(2), 243-253.

O'Campo, P. (2003). Invited commentary: advancing theory and methods for multilevel models of residential neighborhoods and health [Comment]. American Journal of Epidemiology, 157(1), 9-13.

Poortinga, W. (2006). Social capital: an individual or collective resource for health? Social Science \& Medicine, 62(2), 292-302.

Putnam, R. (2000). Bowling alone: The collapse and revival of American community. New York: Simon \& Schuster.

Putnam, R. D. (2007). E Pluribus Unum: diversity and community in the twenty-first century: the 2006 Johan Skytte Prize Lecture. Scandinavian Political Studies, 30(2), 137-174.

Raudenbush, S., \& Sampson, R. (1999). Ecometrics: toward a science of assessing ecological settings, with application to the systematic social observation of neighborhoods. Sociological Methodology, 29, 1-41.

Ross, C. E. (2000a). Neighborhood disadvantage and adult depression. Journal of Health $\mathcal{E}$ Social Behavior, 41(2), 177-187.

Ross, C. E. (2000b). Walking, exercising, and smoking: does neighborhood matter? Social Science $\mathcal{E}$ Medicine, 51(2), 265-274.

Ross, C., Reynolds, J., \& Geis, K. (2000). The contingent meaning of neighborhood stability for residents' psychological well-being. American Sociological Review, 65, 581-597.
Sampson, R. J., \& Raudenbush, S. W. (2004). Seeing disorder: neighborhood stigma and the social construction of "broken windows". Social Psychology Quarterly, 67(4), 319-342.

Sampson, R., Morenoff, J., \& Earls, F. (1999). Beyond social capital: spatial dynamics of collective efficacy for children. American Sociological Review, 64(5), 633-660.

Sampson, R., Raudenbush, S., \& Earls, F. (1997). Neighborhood and violent crime: a multilevel study of collective efficacy. Science, 277, 1-7.

Skogan, W. (1990). Disorder and decline: Crime and the spiral of decay in American cities. Berkely: University of California Press.

STATA Corporation. (2007). Intercooled STATA (Version 9.2 for Windows). STATA Corporation.

Strawbridge, W. J., Shema, S. J., Cohen, R. D., Roberts, R. E., \& Kaplan, G. A. (1998). Religiosity buffers effects of some stressors on depression but exacerbates others. Journals of Gerontology Series B-Psychological Sciences \& Social Sciences, 53(3), S118-126.

Subramanian, S. V., Kim, D. J., \& Kawachi, I. (2002). Social trust and selfrated health in US communities: a multilevel analysis. Journal of Urban Health, 79(4 Suppl. 1).

Subramanian, S. V., Lochner, K. A., \& Kawachi, I. (2003). Neighborhood differences in social capital: a compositional artifact or a contextual construct? Health E' Place, 9(1), 33-44.

Taylor, R. B. (2001). Breaking away from broken windows: Baltimore neighborhoods and the nationwide fight against crime, grime, fear, and decline. Boulder, CO: Westview Press.

Welch, M., Rivera, R., Conway, B., Yonkoski, J., Lupton, P., \& Giancola, R. (2005). Determinants and consequences of social trust. Sociological Inquiry, 75(4), 453-473.

Wilson, J. Q., \& Kelling, G. (1982). Broken Windows. Atlantic Monthly, 211, 29-38.

Yip, W., Subramanian, S. V., Mitchell, A. D., Lee, D. T., Wang, J., \& Kawachi, I. (2007). Does social capital enhance health and wellbeing? Evidence from rural China. Social Science $\mathcal{E}$ Medicine, 64(1), 35-49. 